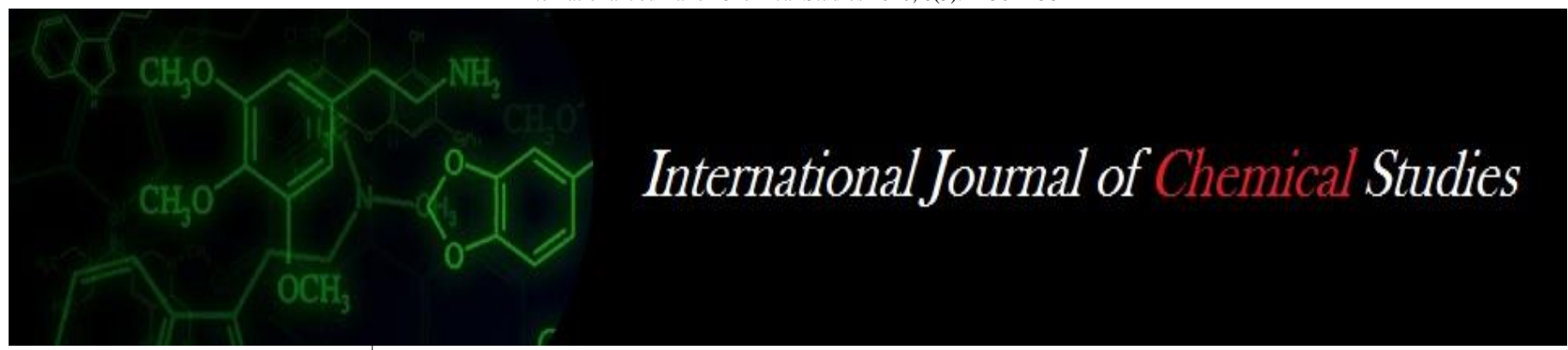

P-ISSN: 2349-8528

E-ISSN: 2321-4902

www.chemijournal.com

IJCS 2020; 8(5): 1256-1258

(C) 2020 IJCS

Received: 15-06-2020

Accepted: 03-08-2020

\section{A Reshma}

Horticultural Research Station, Kovvur, Dr YSR Horticultural University,

Venkataramannagudem, Andhra Pradesh, India

\section{K Mamatha}

Horticultural Research Station, Kovvur, Dr YSR Horticultural University,

Venkataramannagudem, Andhra Pradesh, India

\section{BVK Bhagavan}

Horticultural Research Station, Kovvur, Dr YSR Horticultural University,

Venkataramannagudem, Andhra Pradesh, India

\section{A Snehalatha Rani}

Horticultural Research Station, Kovvur, Dr YSR Horticultural University,

Venkataramannagudem, Andhra Pradesh, India

\section{DR Salomi Suneetha}

Horticultural Research Station, Kovvur, Dr YSR Horticultural University,

Venkataramannagudem, Andhra Pradesh, India

\section{Corresponding Author:}

\section{A Reshma}

Horticultural Research Station, Kovvur, Dr YSR Horticultural University,

Venkataramannagudem, Andhra Pradesh, India

\section{Genetic characterization of seedling progenies of elephant foot yam Amorphophallus paeoniifolius (Dennst.) for quantitative traits through principal component analysis}

\author{
A Reshma, K Mamatha, BVK Bhagavan, A Snehalatha Rani and DR \\ Salomi Suneetha
}

DOI: https://doi.org/10.22271/chemi.2020.v8.i5r.10474

\begin{abstract}
A total of twenty six seedling progenies of elephant foot yam were evaluated for 24 quantitative characters at Horticultural Research Station, Kovvur to determine the pattern of variation, relationship among the individuals and their characteristics. The principal component analysis reduced the data set into seven principal components which explained $84.61 \%$ percent towards variability. The first principal component analysis accounted a maximum of $27.3 \%$ of the total variation and contributed by discriminating traits of pseudo-stem height, plant height, breadth of largest leaflet, height of corm and thickness of pseudo-stem base. In general, this study reveals the presence of diversity among 26 seedling progenies of elephant foot yam which can give opportunity for genetic improvement for desirable characters.
\end{abstract}

Keywords: Principal component, elephant foot yam, variability, genetic improvement

\section{Introduction}

Amorphophallus paeoniifolius (Dennst.) is a herbaceous monoecious $\mathrm{C}_{3}$ crop and is an important tuber crop of tropical and subtropical regions. It serves as a source of protein as well as starch. It has been used as a local staple food in many countries like Philippines, Java, Indonesia, Sumatra, Malaysia, Bangladesh, India, China and South Eastern Asian countries. Owing to its production potential and popularity as a vegetable in various delicious Indian cuisines, it is commercially cultivated in India in the states of Andhra Pradesh, West Bengal, Gujarat, Kerala, Tamil Nadu, Maharashtra, Uttar Pradesh and Jharkhand. In the Northern and Eastern states of India local cultivars grown in wild form are generally being used for making vegetable pickles and indigenous for various ailments. Because of its high yield potential, culinary properties medicinal utility and therapeutic values it is referred to as King of tuber crops (Sengupta et al. 2008) ${ }^{[5]}$. The production potential of this crop varies from 50-60 t /ha and net economic return is over 1 lakh rupees per ha (Ravi et al., 2009) ${ }^{[4]}$. This crop also offers export potential since it is not commercially cultivated in other countries (Misra and Shivalingaswamy, 1999, Misra et al., 2001) ${ }^{[1,2]}$. Elephant foot yam is a highly cross pollinated and vegetatively propagated crop. Though it is reported to be a highly cross pollinated crop, sexual reproduction is reported to be very rare due to scarce flowering, non -synchronization of flowers and the presence of extreme protogyny and hence the vegetative propagation is in common practice.

The knowledge of genetic diversity is very important for conservating, evaluating and utilising genetic resources in breeding programmes such as breeding for required quality, increasing yield, pests and disease resistance. Principal component analysis is one of the important techniques useful for characterisation, evaluation and classification of plant genetic resources based on morphological and agronomic traits when large of accessions are to be assessed for several characters (Peeters and Martinelli, 1989) ${ }^{[3]}$. This procedure permits to establish the relationship among the variables and to determine how the plants vary in terms of all variables considered together. 


\section{Materials and Methods}

The experimental material consists of 26 seedling progenies of elephant foot yam which were being maintained at Horticultural Research Station, Kovvur. Experiment was laid out in an augmented block design consisting of four augmented blocks with six entries per each block. The standard package of practices were followed to raise the crop. Morphological observations for all the 24 quantitative characters were recorded on five randomly selected plants of each accession. Principal component analysis was carried out to find out the relative importance of different traits in capturing the variation.

\section{Results and Discussion}

In the present study, the genetic variation present among the accessions was divided into seven principal components with eigen values more than one which contributed 84.61 percent towards the variability. The principal component with eigen values less than one were considered as non-significant. It is therefore inferred that the essential features of the data set had been represented in the first seven principal components in table 1 and 2 . The first principal component (PC I) contributed maximum towards variability (27.389)and the characters viz., pseudo-stem height (0.339), plant height (0.334), breadth of largest leaflet $(0.301)$, height of corm (0.294), thickness of pseudo-stem base (0.284) explained the maximum variance in this component. The second principal component (PC II) described 16.56 percent of total variance and the characters viz., weight of cormels per plant $(0.354)$, length of cormel (0.352), thickness of cormel (0.320), number of leaflets per primary partition (-0.318) explained the maximum variance. The third principal component PC III was characterised by 13.422 percent contribution towards variability and the characters viz., number of primary partitions (0.395), diameter of corm (0.082), pseudo-stem height (0.058), plant height (0.054) contributed in a positive way, whereas number of secondary partitions $(-0.39)$ showed negative correlation towards the total variability. The fourth principal component PC IV was characterised by 10.638 percent contribution towards the total variability and showed high loadings for the characters., days to senescence (0.372), fresh weight of corm $(0.256)$ and yield $(0.256)$ in a positive way, whereas the trait oxalates percent (-0.442) showed negative correlation towards the variability. The fifth principal component PC V was characterised by 7.146 percent contribution towards the variability. The characters length of largest leaflet (0.459), oxalates percent $(0.369)$ has shown the highest positive contribution towards variability and the traits breadth of primary partition (-0.458), length of primary partition $(-0.403)$ and starch content $(-0.314)$ has shown the negative correlation towards the total variability. The sixth principal component PC VI explained about 5.383 percent variability. The characters viz., starch percent $(0.601)$, breadth of largest leaflet (0.286), number of leaves per rachis $(0.258)$, diameter of corm (0.240) has contributed towards the variability, whereas the trait number of leaflets per rachis ($0.269)$, fresh weight of corm per plant $(-0.242)$ has shown the negative correlation towards the variability.

Table 1: Eigen values, per cent variability and cumulative variability for principal components of morphological characters in elephant foot yam

\begin{tabular}{|c|c|c|c|c|}
\hline SI. No. & Principal component & Eigen value (Root) & Percent variation explained & Cumulative variation explained \\
\hline 1 & 1 Vector & 6.57 & 27.38 & 27.38 \\
\hline 2 & 2 Vector & 3.97 & 16.56 & 43.94 \\
\hline 3 & 3 Vector & 3.22 & 13.42 & 57.37 \\
\hline 4 & 4 Vector & 2.55 & 10.63 & 68.00 \\
\hline 5 & 5 Vector & 1.71 & 7.14 & 75.15 \\
\hline 6 & 6 Vector & 1.29 & 5.38 & 80.53 \\
\hline 7 & 7 Vector & 0.97 & 4.07 & 84.61 \\
\hline
\end{tabular}

Table 2: Character loading of principal components for morphological characters in elephant foot yam

\begin{tabular}{|c|c|c|c|c|c|c|c|c|}
\hline Sl. No. & Character & 1 Vector & 2 Vector & 3 Vector & 4 Vector & 5 Vector & 6 Vector & 7 Vector \\
\hline 1 & Plant height $(\mathrm{cm})$ & 0.333 & 0.085 & 0.054 & 0.112 & 0.074 & 0.055 & 0.142 \\
\hline 2 & Pseudo-stem height $(\mathrm{cm})$ & 0.339 & 0.075 & 0.057 & 0.119 & 0.050 & 0.117 & 0.142 \\
\hline 3 & Thickness of pseudo-stem base $(\mathrm{cm})$ & 0.284 & 0.078 & -0.127 & -0.244 & -0.029 & -0.144 & -0.056 \\
\hline 4 & Leaves per rachis & 0.004 & 0.08 & -0.211 & 0.100 & -0.126 & 0.257 & -0.689 \\
\hline 5 & Leaflets per rachis & 0.194 & 0.045 & -0.144 & -.0429 & -0.011 & -0.268 & -0.220 \\
\hline 6 & Primary partitions & -0.025 & 0.299 & 0.395 & -0.058 & -0.003 & -0.073 & -0.161 \\
\hline 7 & Secondary partition & 0.014 & -0.310 & -0.391 & 0.058 & 0.006 & 0.071 & 0.141 \\
\hline 8 & Tertiary partitions & 0.069 & -0.310 & -0.285 & -0.066 & 0.143 & -0.175 & -0.107 \\
\hline 9 & Length of primary partition $(\mathrm{cm})$ & 0.209 & 0.175 & -0.142 & -0.222 & -0.402 & -0.081 & 0.084 \\
\hline 10 & Breadth of primary partition $(\mathrm{cm})$ & 0.160 & 0.211 & -0.051 & -0.189 & -0.457 & -0.004 & 0.255 \\
\hline 11 & Leaflets/primary partition & 0.066 & -0.317 & -0.232 & -0.047 & -0.211 & -0.002 & 0.148 \\
\hline 12 & Length of largest leaflet $(\mathrm{cm})$ & 0.219 & -0.109 & 0.000 & -0.131 & 0.458 & 0.137 & -0.177 \\
\hline 13 & Breadth of largest leaflet $(\mathrm{cm})$ & 0.300 & -0.004 & 0.048 & -0.211 & -0.001 & 0.286 & -0.051 \\
\hline 14 & Days to senescence & 0.142 & -0.044 & -0.226 & 0.371 & 0.044 & -0.190 & 0.218 \\
\hline 15 & Fresh weight of corm per plant $(\mathrm{kg})$ & 0.307 & 0.050 & -0.072 & 0.256 & 0.002 & -0.242 & -0.209 \\
\hline 16 & Height of corm $(\mathrm{cm})$ & 0.293 & 0.159 & 0.048 & 0.076 & 0.141 & 0.179 & 0.082 \\
\hline 17 & Diameter of corm $(\mathrm{cm})$ & 0.266 & 0.109 & 0.081 & 0.147 & 0.150 & 0.239 & 0.187 \\
\hline 18 & Cormels per corm & -0.122 & 0.310 & -0.335 & 0.134 & 0.117 & -0.072 & 0.001 \\
\hline 19 & Weight of cormels per corm $(\mathrm{g})$ & -0.107 & 0.353 & -0.260 & -0.092 & 0.124 & -0.017 & 0.038 \\
\hline 20 & Length of cormel $(\mathrm{cm})$ & -0.143 & 0.351 & -0.265 & -0.068 & 0.100 & 0.022 & -0.021 \\
\hline 21 & Thickness of cormel $(\mathrm{cm})$ & -0.141 & 0.320 & -0.276 & 0.157 & 0.091 & 0.160 & 0.147 \\
\hline 22 & Yield (t/ha) & 0.307 & 0.050 & -0.072 & 0.256 & 0.002 & -0.242 & -0.209 \\
\hline 23 & Starch $(\%)$ & 0.027 & -0.091 & -0.145 & 0.098 & -0.313 & 0.600 & -0.136 \\
\hline 24 & Oxalates (\%) & 0.014 & -0.02 & -0.149 & -0.441 & 0.369 & 0.196 & 0.164 \\
\hline
\end{tabular}




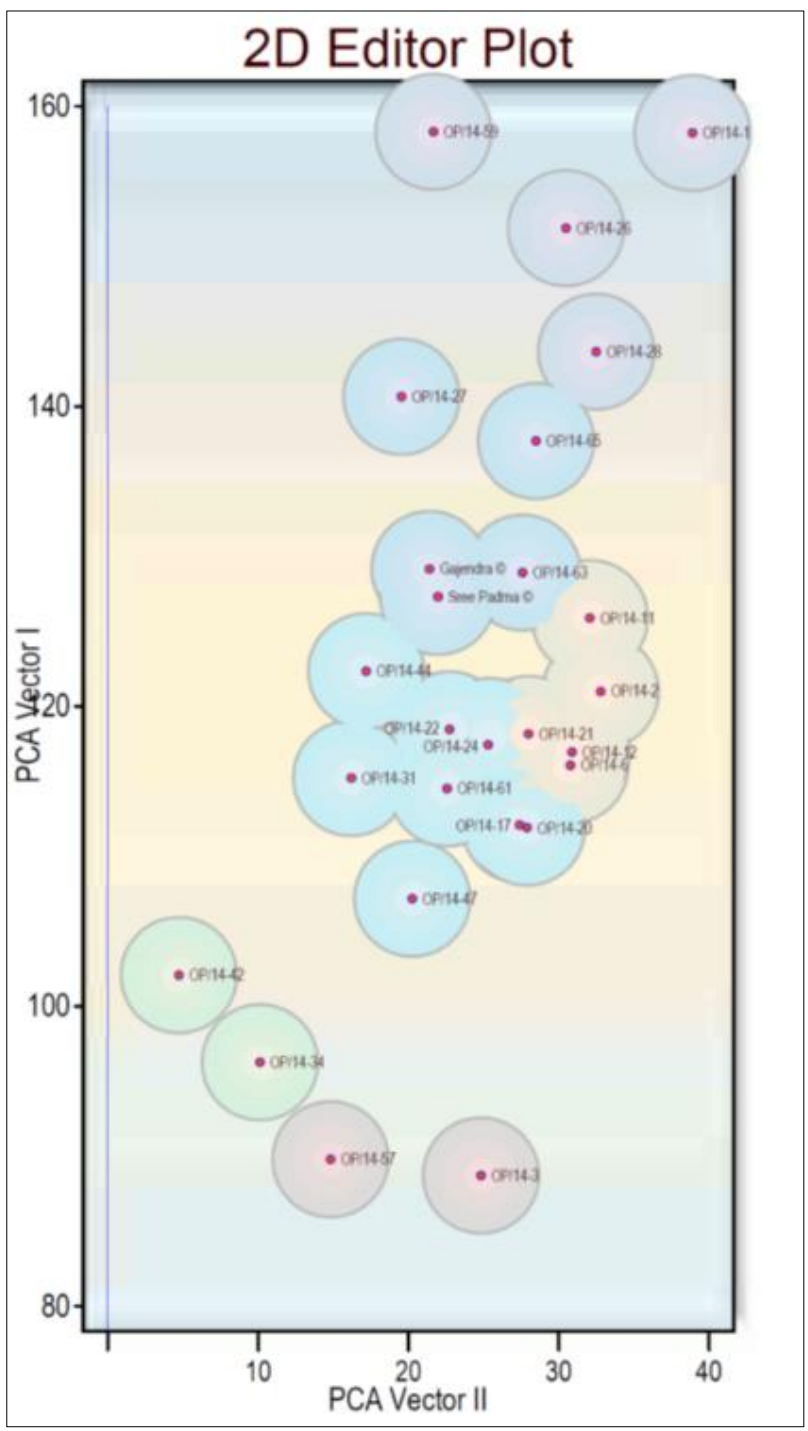

Fig 1: Relative position of elephant footyam accessions based on PCA scores of growth and yield parameters

The seventh principal component PC VII has described 4.075 percent variability. Among the characters breadth of primary partition (0.255), days to senescence (0.219) and diameter of corm (0.187) has shown positive correlation towards the variability whereas the number of leaves per rachis $(-0.689)$, number of leaflets per rachis $(-0.220)$ and fresh weight of corm $(-0.209)$ has exhibited negative correlation towards the variability.

Results thus obtained from PCA using correlation matrix of the traits reduced the dimensionality of the data set by creating seven significant principal components having eigen values more than one. The analysis thus identified that maximum contributing variables for diversity were pseudostem height (0.339) and plant height (0.334) for PCA-1. In all the seven components, Plant height, pseudostem height, height of cprm and diameter of corm contributed positively to the total variation and hence these characters can be used for selection in crop improvement programme.

\section{Conclusion}

From the above study, it can be inferred that presence of trait diversity among seedling progenies of elephant foot yam suggests that there is oppurtunity for genetic improvement through selection directly from accessions and selection of diverse parents for hybridization programme and conservation of germplasm for future utilization.

\section{Acknowledgments}

The Authors are thankful to Dr YSR Horticultural University, Venkataramannagudem for providing support.

\section{References}

1. Misra RS, Shivlingaswamy TM. Elephant foot yam: a tropical tuber crop with high yield potential. 4th Agricultural Science Congress, 1999, 21-24.

2. Misra RS, Shivlingaswamy TM, Maheshwari SK. Improved production technology for commercial and seed crops of elephant foot yam. Journal of Root Crops. 2001; 27:197-201.

3. Peeters JP, Martinelli JA. Hierarchial cluster analysis as a tool to manage variation in germplasm collections. Theoretical and applied genetics. 1989; 78:42-48.

4. Ravi V, Ravindran CS, Suja G. Growth and productivity of elephant foot yam Amorphophallus paeoniifolius (Dennst.): An Overview. Journal of Root Crops. 2009; 35(2):131-142.

5. Sengupta S, Chowdhary BM, Singh BN, Ray RN. Status of Elephant foot yam cultivation in Jharkhand. In Palaniswami MS et al. Ed. National Seminar on Amorphaophallus: Innovative technologies, July, 19-20, 2008, Patna, Bihar-Abstract book and extended summary, 2008, 30-34. 